\title{
Genetic Gain in Testcrosses Derived from Heat Tolerant Multi-parental Synthetic Populations of Maize
}

\author{
Muttappa Hosamani $^{1 *}$, I. Shankergoud ${ }^{1}$, P. H. Zaidi ${ }^{2}$, Ayyanagouda Patil ${ }^{1}$, \\ M. T. Vinayan ${ }^{2}$, P. H. Kuchanur ${ }^{1 *}$, K. Seetharam ${ }^{2}$ and Somasekhar ${ }^{1}$ \\ ${ }^{1}$ University of Agricultural Sciences, Raichur-584 104, Karnataka, India \\ ${ }^{2}$ International Maize and Wheat Improvement Center (CIMMYT) - Asia, ICRISAT Campus, \\ Patancheru-502324, Hyderabad, India \\ *Corresponding author
}

\section{Keywords}

Maize, Testcrosses, Multi-parent population (MPS), Genetic gain

Article Info

Accepted:

15 December 2019

Available Online:

20 January 2020

\section{A B S T R A C T}

Heat stress due to prolonged high ambient temperature during critical growth stages is a serious threat to crop production worldwide. Though being a $\mathrm{C}_{4}$ crop, maize has relatively wider adaptation, however, weather extremes such as heat stress is challenging its threshold limits. There is an absolute requirement of heat tolerant cultivars in the present condition as climate change has a become reality. This study was designed to assess the genetic gain in various stress-adaptive traits of maize testcrosses derived from two heat tolerant heterotic multi-parental synthetic (MPS 1 and MPS 2) populations. The trial consisted of $405 \mathrm{~F}_{2: 3}$ testcrosses derived from MPS 1 along with two commercial checks and $470 \mathrm{~F}_{2: 3}$ testcrosses derived from MPS 2 along with five commercial checks. They were evaluated in Alpha lattice design with two replications at Main Agriculture Research Station, Raichur, Karnataka during spring season where the most part of reproductive stage, starting from tassel emergence until late grain filling, was exposed to heat stress. Analysis of variance revealed that the mean sum of squares due to genotypes in MPS 1 differed significantly for grain yield and MPS 2 showed significant variation among genotypes for all the characters studied, indicating the presence of variability for all the traits in the germplasm utilized for present study. The top 10 per cent of the $F_{2: 3}$ families of MPS 1 and MPS 2 populations were selected based on their testcross performance and subjected to genetic gain study. The maximum genetic gain was observed for grain yield $(58.55 \%)$, days to 50 per cent anthesis $(-2.05 \%)$, days to 50 per cent silking $(-2.24 \%)$, ASI $(-3.35 \%)$, plant height $(4.25 \%)$ and ear height $(5.49 \%)$ in MPS 1 population compared to MPS 2 population. These results suggest that, a new and advanced elite heat tolerance lines isolated from the early segregating progeny that produced very good testcrosses in different heterotic groups. These elite heat tolerant lines would be useful to maize breeders for improving heat stress resilience in maize. 


\section{Introduction}

Maize (Zea mays L.; $2 \mathrm{n}=20$ ) is a major cereal crop worldwide, serving as an important staple for both human consumption and animal feed. It is grown throughout the world in a wide range of agro-ecological environments. Maize has the highest grain yield potential per hectare than other cereals. Hence, it is known as 'queen of cereals'. Maize is widely cultivated in diverse conditions ranging from $58^{\circ} \mathrm{N}$ to $40^{\circ} \mathrm{S}$, from below sea level to altitudes higher than 3000 meters and in areas with $250 \mathrm{~mm}$ to more than $5000 \mathrm{~mm}$ of rainfall per year due to wide genetic diversity of the crop (Shaw, 1988; Dowswell et al., 1996). Origin of maize is the Central America and Mexico, as the maximum maize genetic diversity exits in this region.

Globally, maize is cultivated in an area of $183.24 \mathrm{~m}$ ha with the production of 1036.07 $\mathrm{m} \mathrm{t}$ and productivity of $5.65 \mathrm{t} \mathrm{ha}^{-1}$ (Anon, 2018a). Among the maize growing countries, USA stands first followed by Brazil, China and Mexico. India stands sixth among the maize producing countries in the world with an area, production and productivity of $9.6 \mathrm{~m}$ ha, $27.15 \mathrm{~m} \mathrm{t}$ and $2.83 \mathrm{t} \mathrm{ha}^{-1}$, respectively (Anon, 2018b). Further, productivity of maize in India is lower than world average, may be due to 70-75 per cent area is under rainfed condition, where, crop suffers from heat and/or drought stress. Karnataka is one of the major maize producing states in the country with an area of $1.29 \mathrm{~m}$ ha, production $3.55 \mathrm{~m} \mathrm{t}$ and productivity $2755 \mathrm{~kg} \mathrm{ha}^{-1}$ (Anon, 2018b). The other states contributing to the national production are Madhya Pradesh, Uttar Pradesh, Bihar, Tamil Nadu, Maharashtra, Andhra Pradesh, Rajasthan and Gujarat.

With the ever increasing population worldwide, there is an exponential increase in the demand for food. In order to meet the food requirements of the burgeoning population, the area under the agricultural production must be increased and also the productivity per unit area must be enhanced. But global climate change patterns are hindering the production and productivity by causing various kinds of stresses.

Heat stress can be defined as exposure to temperatures (maximum and/or minimum) above a threshold level for a period of time that causes irreversible damage to crop growth and development and is a function of the intensity, duration and rate of increase in temperature (Zaidi et al., 2016). It has been predicted that growing season temperatures in the tropics and subtropics will exceed even the most extreme seasonal temperatures so far (Battisti and Naylor, 2009).

Maize is highly productive under optimal growing conditions and crop management conditions and does reasonably well under sub-optimal conditions, but susceptible to severe drought and heat. Every year an average of 15 to 20 per cent of the world maize production is lost due to drought and heat stresses. High temperatures have profound impact on yield compared to drought in maize (Lobell et al., 2011). Being grown is diverse conditions and throughout the year, maize is at highest risk of extreme temperatures compared to wheat and soybean worldwide (Deryng et al., 2014).

Genetic gain (GG) is usually estimated in field crops as the collective contribution of several breeding programmes. For the individual breeder, however, the genetic gain realized within a single programme is critical (Mohammadi, 2012). Information on the genetic gains in improvement of grain yield and other traits in crops may help identify traits of potential value as well as the necessary modifications in breeding methodologies and strategies for increased progress in future breeding efforts (Apraku et 
al., 2014). The difference between the mean phenotypic value of the progeny of selected plants and the base or parental population is known as genetic gain. This is usually used to refer to the increase after one generation has passed. To increase genetic gain, phenotyping can contribute toward improving selection intensity, selection accuracy and even identifying new genetic variation. Phenotyping is crucial for ongoing efficient targeting of novel genetic variation to incorporate it into breeding programmes for sustained long-term genetic gain. In addition to assessment of genetic gains in breeding programme genetic gain helps critical analysis of efficiency and plan new strategies.

In maize breeding programmes, development of base population is a prerequisite to isolate inbred lines. International Centre for Maize and Wheat Improvement (CIMMYT) Asia, Hyderabad has identified several lines tolerant to heat and other abiotic stresses. These inbred lines were used to produce the multiparental synthetics for isolation of next cycle inbred lines from the synthetic population.

Hence, there is need to select plants that are tolerant to heat stress for advancing them to next generation of selfing to isolate inbred lines tolerant to heat stress. Therefore, $F_{2: 3}$ selected plants derived from multi-parental synthetics were crossed with the proven testers viz., CL02450 and CML451 belonging to two heterotic groups. Keeping these things in view, the present investigation was undertaken to assess the genetic gain of maize testcrosses of multi-parental synthetic (MPS 1 and MPS 2) populations under heat stress condition.

\section{Materials and Methods}

The experimental material comprised of 405 $\mathrm{F}_{2: 3}$ testcrosses derived from a heat tolerant multiparent synthetic (MPS 1) belongs to heterotic group A and crossed with tester CML 451 belongs to heterotic group $\mathrm{B}$ and $470 \mathrm{~F}_{2: 3}$ testcrosses from MPS-2, a heterotic group $\mathrm{B}$ population crossed with tester CL02540 belongs to heterotic group A. The testcrosses of MPS 1 were evaluated along with two popular commercial checks (31Y45 and DKC9108), while the testcrosses of MPS 2 were evaluated with five popular commercial checks (31Y45, DKC9108, HTMH5401, NK6240 and Pio3396) in spring season. The testcrosses were evaluated in Alpha lattice design with two replications at Main Agriculture Research Station, Raichur, Karnataka during spring season, where trial was exposed to high temperature regime (Tmax 37 to $>40{ }^{\circ} \mathrm{C}$ ) during summer-2014 (March-May). Each entry was raised in single row of $4 \mathrm{~m}$ length with a spacing of $60 \mathrm{~cm} \mathrm{x}$ $20 \mathrm{~cm}$.

After thorough land preparation, sowing was done by hand dibbling of seeds with two seeds per hill and later thinned to retain one seedling per hill. Then the plot was irrigated. The recommended dose of fertilizers $(150 \mathrm{~N}$, $75 \mathrm{P}_{2} \mathrm{O}_{5}$ and $37.5 \mathrm{~K}_{2} \mathrm{O} \mathrm{kg} \mathrm{ha}{ }^{-1}$ ) was given to the crop. The entire dose of $\mathrm{P}_{2} \mathrm{O}_{5}, \mathrm{~K}_{2} \mathrm{O}$ and one third of nitrogen was applied as basal dose and remaining two-third nitrogen was top dressed in two equal splits at fourth and seventh week after planting. Standard package of practices were adopted to raise a healthy crop.

Testcrosses of each MPS populations were evaluated for days to 50 per cent anthesis, days to 50 per cent silking, anthesis-silking interval, plant height $(\mathrm{cm})$, ear height $(\mathrm{cm})$ and grain yield per plot (which was later scale to $\mathrm{t} \mathrm{ha}^{-1}$ at $12 \%$ grain moisture) under heat stress condition (Data not shown). Based on BLUP (i.e., phenotypic data only) of grain yield of $\mathrm{F}_{2: 3}$ testcrosses were used to develop a phenotypic selection index under heat stress 
condition. The $\mathrm{F}_{2: 3}$ testcrosses were ranked according to the value of the phenotypic selection index. The top 10 per cent of the $F_{2: 3}$ families (41 entries in MPS 1 and 47 entries in MPS 2) with the highest selection index values were selected based on their testcross performance (Table 2 and 3). The remnant selfed seeds of $\mathrm{F}_{2: 3}$ families that produced superior testcross progenies were planted in ear-to-row and intermated to form Cycle 1 at CIMMYT-Asia, ICRISAT camps, Hyderabad for genomic selection study.

Analysis of variance for individual characters was carried out on the basis of mean value per entry per replication as suggested by Patterson and Williams (1976) for Alfa lattice design. Analysis was required to test whether the genotypes differed significantly among themselves or not. Estimation of genetic gain for each population in each character was calculated by following formula:

Genetic gain = Mean of selected families/progeny - Mean of the parental population

Genetic gain $(\%)=$ Mean of selected families/progeny - Mean of the parental population

Mean of the parental population

\section{Results and Discussion}

The extent of variability for various quantitative traits available to the breeder determines the success that can be achieved in genetic improvement of that species. The mean sum of squares due to genotypes showed highly significant differences for all the characters in MPS 2 and only grain yield in MPS 1 population (Table1) indicating the presence of adequate variability for improvement among the families. Similar results were reported by Angadi (2014),
Dinesh (2015) and Ranganath (2015) for all characters except anthesis silking interval under heat stress condition.

The proportion of superior inbred lines is determined by the proportion of the superior genotypes in the base population and the effectiveness of selection during the inbreeding. Hence, selection of proper germplasm source is an essential part of breeding programme. The breeding methods, efficiency of selection and final success are highly dependent on the base population chosen. Tannar and Smith (1987) studied various maize population derived from synthetics using two methods of recurrent selection and population derived from open pollinated variety based on the changes in grain yield, grain moisture and lodging. Their study indicated the importance of effective population size and selection during $S_{1}$ or $S_{2}$ was more effective in eliminating unfavourable allele in the population.

The mean per se performance of MPS 1 and MPS 2 population testcrosses was promising under heat stress condition (Data not shown). The top 10 per cent of the best performing MPS 1 (Table 2) and MPS 2 (Table 3) $\times 100$ population testcrosses were identified based on their per se performance in comparison with the local checks in each population. The genetic gains by selecting top performing $(10 \%)$ testcrosses of MPS populations belonging to two different heterotic groups for selected traits studied in the present investigation under heat stress condition are presented in Table 4.

The reduction in anthesis under heat stress condition is desirable for any commercial maize crop indicating earliness. In the present investigation, under heat stress condition, mean per se performance of selected testcrosses derived from MPS 1 population for days to 50 per cent anthesis ranged from 
48.50 (ZH133864 and ZH133948) to 57.00 (ZH133687 and ZH133989) days with a mean of 52.46 days as compared to population mean of 53.56 days (Table 2). Among the $\mathrm{F}_{2: 3}$ families, top 10 per cent of the $F_{2: 3}$ families took less number of days than check hybrid 31 Y45 (53.50 days). These selected $F_{2: 3}$ maize families provided a gain of -1.10 days representing -2.05 per cent improvement over the base population (Table 4). While, in the selected testcrosses derived from MPS 2 population, per se performance ranged from 48.50 (ZH13743) to 55.50 (ZH13548) days with a mean of 51.90 days as compared to base population of 53.00 days (Table 3). Among the $\mathrm{F}_{2: 3}$ families, top 10 per cent of the $F_{2: 3}$ families showed earliness than the check hybrid 31Y45 (54.50 days). These selected $\mathrm{F}_{2: 3}$ maize families provided a gain of -1.10 days representing -2.07 per cent improvements over the population (Table 4). This was consistent with the findings of Ranganath (2015) who noticed an average gain of -5.00 per cent under heat stress conditions.

The per se performance of selected testcrosses derived from MPS 1 population for days to 50 per cent silking ranged from 51.00 (ZH133864) to 60.00 (ZH133687, ZH133929 and ZH133969) days with a mean of 55.80 days as compared to population mean of 57.08 days (Table 2). Among the $F_{2: 3}$ families, top 10 per cent of the $F_{2: 3}$ families recorded earliness than check hybrid 31Y45 (58.00 days). These selected $\mathrm{F}_{2: 3}$ maize families provided a gain of -1.28 days representing -2.24 per cent improvement over the base population (Table 4). While, in the selected testcrosses derived from MPS 2 population, per se performance ranged from 51 (ZH13642) to 59.00 (ZH13548) days with a mean of 55.09 days as compared to base population of 56.29 days (Table 3). Among the $F_{2: 3}$ families, top 10 per cent of the $F_{2: 3}$ families showed earliness in silking than the check hybrid 31Y45 (55.50 days). These selected $\mathrm{F}_{2: 3}$ maize families provided a gain of -1.20 days representing -2.13 per cent improvements over the population (Table 4). Ranganath (2015) reported the genetic gain of -6.00 per cent for this trait under heat stress condition.

The reduction in anthesis-silking interval (ASI) under optimal and heat stress condition is desirable for any commercial maize cultivar indicating good general synchrony between both male and female flowering times. In the present investigation, under heat stress condition, the mean per se performance of selected testcrosses derived from MPS 1 population for ASI ranged from 0.50 (ZH133930) to 7.00 (ZH133929) days with a mean of 3.26 days as compared to population mean of 3.38 days (Table 2). Among the $F_{2: 3}$ families, top 10 per cent of the $F_{2: 3}$ families recorded less number of days than check hybrid 31Y45 (4.50 days). These selected $F_{2: 3}$ maize families provided a gain of -0.12 days representing -3.55 per cent improvement over the population (Table 4). In MPS 2 population, ASI of selected testcrosses per se performance ranged from 1.50 (ZH13642) to 6.50 (ZH13660) days with a mean of 3.18 days as compared to base population of 3.29 days (Table 3). Among the $F_{2: 3}$ families, top 10 per cent of the $F_{2: 3}$ families took more number of days than the check hybrid 31Y45 (1.00 days). However, the selected $\mathrm{F}_{2: 3}$ maize families provided a gain of -0.11 days representing -3.45 per cent improvements over the population under heat stress condition (Table 4). Alam et al. (2017) reported that, an ASI of 2-4 days and pollen shedding duration (PSD) of 2-4 days were found advantageous to grain yield under heat stress. Stigma receptivity was less affected under heat stress when compared to pollen viability, yet stigma initiation was delayed under heat stress, which resulted in prolonged ASI. 
Increased plant height is desirable as plant height decreases under heat stress due to restricted inter-nodal elongation. Further, grain yield is positively correlated with plant height and hence plant height is a major concern for improving maize performance under heat stress (Angadi, 2014). Under heat stress condition, per se performance of selected testcrosses derived from MPS 1 population for plant height ranged from 135.00 (ZH133875) to 172.15 (ZH133948) $\mathrm{cm}$ with a mean of $153.71 \mathrm{~cm}$ as compared to base population mean of $147.44 \mathrm{~cm}$ (Table 2). Among the $\mathrm{F}_{2: 3}$ families, top 10 per cent of the $\mathrm{F}_{2: 3}$ families demonstrated lower plant height compared to the check hybrid 31Y45 $(164.33 \mathrm{~cm})$. These selected $\mathrm{F}_{2: 3}$ maize families provided a gain of $6.27 \mathrm{~cm}$ representing 4.25 per cent improvement over the population (Table 4). While, the per se performance of testcrosses derived from MPS 2 population for this trait ranged from 143.83 (ZH13737) to 187.83 (ZH13650) $\mathrm{cm}$ with a mean of $165.66 \mathrm{~cm}$ compared to population mean of $161.26 \mathrm{~cm}$ (Table 3). Among the $\mathrm{F}_{2: 3}$ families, top 10 per cent of the $\mathrm{F}_{2: 3}$ families recorded lower plant height than the check hybrid 31 Y45 $(174.83 \mathrm{~cm})$. These selected $\mathrm{F}_{2: 3}$ maize families provided a gain of $4.40 \mathrm{~cm}$ representing 2.72 per cent improvements over the population (Table 4). Similar result was found by Ranganath (2015), who reported genetic gain of 12 per cent for this trait under heat stress condition.

Mean per se performance of selected testcrosses derived from MPS 1 population for ear height ranged from 68.80 (ZH133922) to 105.00 (ZH133787) $\mathrm{cm}$ with a mean of $86.22 \mathrm{~cm}$ as compared to base population mean of $81.73 \mathrm{~cm}$ under heat stress condition (Table 2). Among the $\mathrm{F}_{2: 3}$ families, top 10 per cent of the $\mathrm{F}_{2: 3}$ families took lower plant height than the check hybrid 31Y45 (92.75 $\mathrm{cm})$. These selected $\mathrm{F}_{2: 3}$ maize families provided a gain of $4.49 \mathrm{~cm}$ representing 5.49 per cent improvement over the population
(Table 4). In MPS 2 population, the per se performance of testcrosses for this trait ranged from 77.50 (ZH13737) to 107.00 (ZH13644) $\mathrm{cm}$ with a mean of $93.41 \mathrm{~cm}$ compared to population mean of $90.25 \mathrm{~cm}$ (Table 3). Among the $\mathrm{F}_{2: 3}$ families, top 10 per cent of the $\mathrm{F}_{2: 3}$ families recorded lower ear height than the check hybrid 31Y45 (93.50 $\mathrm{cm})$. These selected $\mathrm{F}_{2: 3}$ maize families provided a gain of $3.16 \mathrm{~cm}$ representing 3.50 per cent improvements over the population (Table 4).

Under heat stress condition, mean per se performance of selected testcrosses derived from MPS 1 population for grain yield ranged from 7.92 (ZH133866) to $11.45 \mathrm{t} \mathrm{ha}^{-1}$ (ZH133557) with a mean of $8.80 \mathrm{t} \mathrm{ha}^{-1}$ as compared to base population mean of $5.55 \mathrm{t}$ $\mathrm{ha}^{-1}$ (Table 2). Among the $\mathrm{F}_{2: 3}$ families, top 10 per cent of the $\mathrm{F}_{2: 3}$ families demonstrated very good test cross performance for grain yield compared to the heat resilient check hybrid 31Y45 $\left(7.12 \mathrm{t} \mathrm{ha}^{-1}\right)$. These selected $\mathrm{F}_{2: 3}$ maize families provided a gain of $3.25 \mathrm{t} \mathrm{ha}^{-1}$ representing 58.55 per cent improvement over the base population (Table 4). While, per se performance of selected testcrosses derived from MPS 2 population for this trait ranged from 9.05 (ZH13731) to $11.59 \mathrm{t} \mathrm{ha}^{-1}$ (ZH13707) $\mathrm{t} \mathrm{ha}^{-1}$ with a mean of $9.787 \mathrm{t} \mathrm{ha}^{-1}$ as compared to base population mean of 6.99 t ha $^{-1}$ (Table 3).

Among the $\mathrm{F}_{2: 3}$ families, top 10 per cent of the $F_{2: 3}$ families demonstrated inferior test cross performance for grain yield than heat resilient check hybrid 31Y45 (11.35 $\left.\mathrm{t} \mathrm{ha}^{-1}\right)$. These selected $\mathrm{F}_{2: 3}$ maize families provided a gain of $2.79 \mathrm{t} \mathrm{ha}^{-1}$ representing 39.91 per cent improvements over the population under heat stress condition (Table 4). Ranganath (2015) reported by evaluating testcrosses under heat stress condition that the grain yield showed genetic gain of 35.00 per cent improvement over the base population. 
Table.1 Analysis of variance for various characters in testcrosses derived from multi-parental synthetic (MPS 1 and MPS 2) populations of maize evaluated under heat stress condition

\begin{tabular}{|c|c|c|c|c|c|c|c|c|c|c|c|c|c|c|}
\hline \multirow{2}{*}{$\begin{array}{c}\text { Source of } \\
\text { variance }\end{array}$} & \multirow[t]{2}{*}{ DF } & \multicolumn{6}{|c|}{ MPS 1} & \multirow[t]{2}{*}{ DF } & \multicolumn{5}{|c|}{ MPS 2} & \\
\hline & & $\mathrm{AD}$ & SD & ASI & PH & $\mathrm{EH}$ & GY & & $\mathrm{AD}$ & SD & ASI & $\mathrm{PH}$ & $\mathrm{EH}$ & GY \\
\hline Replication & 1 & 0.21 & 34.66 & 17.08 & 239.78 & 69.94 & 103.16 & 1 & 160.14 & 69.14 & 18.74 & 325.36 & 627.33 & 3.68 \\
\hline Block(Rep) & 80 & 7.72 & 9.14 & 2.91 & 430.96 & 283.32 & 6.10 & 94 & 5.21 & 5.71 & 2.95 & 212.01 & 111.60 & 3.48 \\
\hline Treat & 406 & 5.44 & 7.54 & 2.44 & 293.10 & 179.97 & $5.33^{*}$ & 474 & $6.38 * *$ & $6.63 * *$ & $2.55^{* *}$ & $210.268 *$ & $129.93 *$ & $4.96 * *$ \\
\hline Error & 326 & 5.18 & 8.07 & 2.48 & 305.80 & 178.61 & 4.23 & 380 & 3.56 & 4.01 & 1.91 & 175.53 & 107.61 & 3.83 \\
\hline
\end{tabular}

* Significant at $\mathrm{P}=0.05, * *$ Significant at $\mathrm{P}=0.01$

AD: Days to $50 \%$ anthesis; SD: Days to $50 \%$ silking; ASI: Anthesis to silking interval; PH: Plant height (cm); EH: Ear height (cm); GY: Grain yield (t ha-1)

Table.4 Mean per se performance of testcrosses and per cent gain under heat stress condition for selected traits of maize

\begin{tabular}{|c|c|c|c|c|c|c|c|c|c|c|c|c|c|c|c|c|c|c|}
\hline \multirow{2}{*}{$\begin{array}{c}\text { Popula } \\
\text {-tions }\end{array}$} & \multicolumn{6}{|c|}{ Mean of parental/base population } & \multicolumn{6}{|c|}{ Mean of top $10 \%$ selected families } & \multicolumn{6}{|c|}{ \% Gain over population mean } \\
\hline & $\begin{array}{l}\text { AD } \\
\text { (d) }\end{array}$ & SD (d) & $\begin{array}{c}\text { ASI } \\
\text { (d) }\end{array}$ & $\begin{array}{c}\text { PH } \\
(\mathbf{c m})\end{array}$ & $\begin{array}{c}\mathbf{E H} \\
(\mathbf{c m})\end{array}$ & $\begin{array}{c}\text { GY } \\
\left(\mathbf{t ~ h a}^{-1}\right)\end{array}$ & $\begin{array}{l}\text { AD } \\
\text { (d) }\end{array}$ & SD (d) & $\begin{array}{c}\text { ASI } \\
\text { (d) }\end{array}$ & PH (cm) & $\begin{array}{c}\mathbf{E H} \\
(\mathbf{c m})\end{array}$ & $\begin{array}{c}\text { GY } \\
\left(\mathbf{t ~ h a}^{-1}\right)\end{array}$ & $\begin{array}{l}\text { AD } \\
\text { (d) }\end{array}$ & SD (d) & $\begin{array}{c}\text { ASI } \\
\text { (d) }\end{array}$ & $\begin{array}{l}\text { PH } \\
(\mathbf{c m})\end{array}$ & $\begin{array}{c}\text { EH } \\
(\mathbf{c m})\end{array}$ & $\begin{array}{c}\text { GY } \\
\left(\mathbf{t ~ h a}^{-1}\right)\end{array}$ \\
\hline MPS1 & 53.56 & 57.08 & 3.38 & 147.44 & 81.73 & 5.55 & 52.46 & 55.80 & 3.26 & 153.71 & 86.22 & 8.80 & -2.05 & -2.24 & -3.35 & 4.25 & 5.49 & 58.55 \\
\hline \multicolumn{7}{|c|}{31 Y45 (Check) } & 53.50 & 58.00 & 4.50 & 164.33 & 92.75 & 7.12 & & & & & & \\
\hline MPS2 & 53.00 & 56.29 & 3.29 & 161.26 & 90.25 & 6.99 & 51.90 & 55.09 & 3.18 & 165.66 & 93.41 & 9.78 & -2.07 & -2.13 & -3.45 & 2.72 & 3.50 & 39.91 \\
\hline \multicolumn{7}{|c|}{31 Y45 (Check) } & 54.50 & 55.50 & 1.00 & 174.83 & 93.50 & 11.35 & & & & & & \\
\hline
\end{tabular}

$\mathrm{AD}=$ Days to 50 per cent anthesis (d), SD = Days to 50 per cent silking (d), ASI = Anthesis Silking Interval (d), PH = Plant height $(\mathrm{cm}), \mathrm{EH}=\mathrm{Ear}$ height $(\mathrm{cm})$ and $\mathrm{GY}=$ Grain yield $\left(\mathrm{t} \mathrm{ha} \mathrm{a}^{-1}\right)$ 
Table.2 Mean per se performance of selected testcrosses of MPS 1 population under heat stress condition

\begin{tabular}{|c|c|c|c|c|c|c|c|}
\hline SI no & Name & Anthesis & Silking & ASI & Plt ht & Ear ht & GY (t/ha) \\
\hline 1 & ZH133557 & 52.00 & 55.00 & 3.00 & 140.33 & 74.00 & 11.45 \\
\hline 2 & ZH133929 & 53.00 & 60.00 & 7.00 & 157.60 & 92.30 & 11.18 \\
\hline 3 & ZH133932 & 51.00 & 53.00 & 2.00 & 167.00 & 101.00 & 10.78 \\
\hline 4 & ZH133762 & 52.00 & 58.50 & 3.00 & 155.33 & 93.33 & 10.75 \\
\hline 5 & ZH133948 & 48.50 & 51.50 & 3.00 & 172.15 & 88.95 & 10.09 \\
\hline 6 & ZH133870 & 55.50 & 59.00 & 3.50 & 137.15 & 77.10 & 9.92 \\
\hline 7 & ZH133947 & 54.00 & 58.00 & 4.00 & 153.15 & 99.00 & 9.91 \\
\hline 8 & ZH133841 & 52.00 & 56.00 & 4.00 & 138.15 & 72.95 & 9.62 \\
\hline 9 & ZH133787 & 52.50 & 56.50 & 4.00 & 164.30 & 105.00 & 9.42 \\
\hline 10 & ZH133657 & 51.00 & 54.50 & 3.50 & 152.17 & 69.50 & 9.39 \\
\hline 11 & ZH133896 & 53.00 & 57.00 & 4.00 & 158.65 & 92.10 & 9.26 \\
\hline 12 & ZH133984 & 53.00 & 56.00 & 3.00 & 165.30 & 96.30 & 9.05 \\
\hline 13 & ZH133852 & 55.00 & 58.00 & 3.00 & 140.65 & 78.30 & 8.73 \\
\hline 14 & ZH133786 & 51.50 & 53.50 & 2.00 & 159.80 & 88.80 & 8.68 \\
\hline 15 & ZH133875 & 53.50 & 56.00 & 2.50 & 135.00 & 79.10 & 8.64 \\
\hline 16 & ZH133686 & 51.50 & 54.50 & 3.00 & 150.00 & 75.50 & 8.59 \\
\hline 17 & ZH133943 & 51.50 & 55.50 & 4.00 & 155.60 & 83.80 & 8.55 \\
\hline 18 & ZH133939 & 52.00 & 55.50 & 3.50 & 167.50 & 100.30 & 8.51 \\
\hline 19 & ZH133784 & 53.00 & 55.50 & 2.50 & 151.15 & 88.30 & 8.48 \\
\hline 20 & ZH133910 & 52.00 & 54.50 & 2.50 & 160.30 & 91.30 & 8.48 \\
\hline 21 & ZH133930 & 54.00 & 54.50 & 0.50 & 143.80 & 77.80 & 8.48 \\
\hline 22 & ZH133915 & 52.50 & 54.50 & 2.00 & 164.95 & 100.80 & 8.41 \\
\hline 23 & ZH133797 & 51.00 & 53.00 & 2.00 & 141.30 & 81.15 & 8.38 \\
\hline 24 & ZH133677 & 51.50 & 56.00 & 4.50 & 160.00 & 94.33 & 8.35 \\
\hline 25 & ZH133901 & 51.50 & 54.50 & 3.00 & 155.95 & 80.15 & 8.32 \\
\hline 26 & ZH133559 & 49.50 & 54.50 & 5.00 & 136.83 & 96.00 & 8.30 \\
\hline 27 & ZH133681 & 51.50 & 54.50 & 3.00 & 164.17 & 91.33 & 8.27 \\
\hline 28 & ZH133558 & 52.50 & 54.50 & 2.00 & 160.33 & 90.67 & 8.24 \\
\hline 29 & ZH133862 & 53.50 & 56.00 & 2.50 & 171.45 & 100.10 & 8.18 \\
\hline 30 & ZH133902 & 52.00 & 55.00 & 3.00 & 141.65 & 78.30 & 8.14 \\
\hline 31 & ZH133846 & 51.50 & 56.50 & 5.00 & 159.80 & 92.30 & 8.09 \\
\hline 32 & ZH133994 & 55.00 & 59.00 & 4.00 & 154.15 & 84.00 & 8.08 \\
\hline 33 & ZH133687 & 57.00 & 60.00 & 3.00 & 156.67 & 83.17 & 8.06 \\
\hline 34 & ZH133904 & 50.50 & 53.50 & 3.00 & 149.30 & 74.80 & 8.05 \\
\hline 35 & ZH133922 & 53.00 & 59.00 & 6.00 & 147.80 & 68.80 & 8.03 \\
\hline 36 & ZH133969 & 57.00 & 60.00 & 3.00 & 155.15 & 90.30 & 8.03 \\
\hline 37 & ZH133892 & 53.00 & 57.00 & 4.00 & 150.30 & 75.15 & 8.00 \\
\hline 38 & ZH133838 & 52.50 & 55.50 & 3.00 & 154.95 & 80.45 & 7.97 \\
\hline 39 & ZH133864 & 48.50 & 51.00 & 2.50 & 165.65 & 89.65 & 7.97 \\
\hline 40 & ZH133791 & 52.00 & 54.50 & 2.50 & 139.60 & 89.95 & 7.94 \\
\hline \multirow[t]{4}{*}{41} & ZH133866 & 54.00 & 57.00 & 3.00 & 147.00 & 68.95 & 7.92 \\
\hline & $31 Y 45$ & 53.50 & 58.00 & 4.50 & 164.33 & 92.75 & 7.12 \\
\hline & Sample mean & 52.46 & 55.80 & 3.26 & 153.71 & 86.22 & 8.80 \\
\hline & $\begin{array}{c}\text { Population } \\
\text { mean }\end{array}$ & 53.56 & 57.08 & 3.38 & 147.44 & 81.73 & 5.55 \\
\hline
\end{tabular}


Table.3 Mean per se performance of selected testcrosses of MPS 2 population under heat stress condition

\begin{tabular}{|c|c|c|c|c|c|c|c|}
\hline SI no & Name & Anthesis & Silking & ASI & PIt ht & Ear ht & GY (t/ha) \\
\hline 1 & ZH13707 & 49.00 & 54.00 & 5.00 & 184.00 & 99.33 & 11.59 \\
\hline 2 & ZH13665 & 51.00 & 55.50 & 4.50 & 171.67 & 88.17 & 11.24 \\
\hline 3 & ZH13746 & 52.00 & 54.00 & 2.00 & 164.17 & 103.50 & 10.80 \\
\hline 4 & ZH13745 & 49.00 & 52.50 & 3.50 & 174.00 & 95.00 & 10.79 \\
\hline 5 & ZH13660 & 50.50 & 57.00 & 6.50 & 164.50 & 100.50 & 10.76 \\
\hline 6 & ZH13743 & 48.50 & 52.00 & 3.50 & 169.17 & 99.17 & 10.71 \\
\hline 7 & ZH13902 & 53.00 & 55.50 & 2.50 & 163.83 & 79.67 & 10.71 \\
\hline 8 & ZH13768 & 51.00 & 54.00 & 3.00 & 176.67 & 103.50 & 10.58 \\
\hline 9 & ZH13947 & 54.00 & 58.00 & 4.00 & 164.50 & 95.33 & 10.39 \\
\hline 10 & ZH13631 & 50.00 & 52.50 & 2.50 & 167.96 & 95.17 & 10.38 \\
\hline 11 & ZH13710 & 53.00 & 55.50 & 2.50 & 173.67 & 97.17 & 10.28 \\
\hline 12 & ZH131031 & 54.00 & 58.00 & 4.00 & 159.83 & 83.67 & 10.27 \\
\hline 13 & ZH13933 & 54.00 & 56.50 & 2.50 & 145.83 & 81.50 & 10.11 \\
\hline 14 & ZH13602 & 52.00 & 55.50 & 3.50 & 174.33 & 94.67 & 9.94 \\
\hline 15 & ZH13911 & 51.50 & 54.50 & 3.00 & 164.50 & 90.67 & 9.85 \\
\hline 16 & ZH13674 & 53.00 & 55.50 & 2.50 & 168.17 & 93.83 & 9.82 \\
\hline 17 & ZH13961 & 54.00 & 56.50 & 2.50 & 166.17 & 95.33 & 9.77 \\
\hline 18 & ZH131035 & 55.00 & 58.50 & 3.50 & 161.00 & 88.50 & 9.76 \\
\hline 19 & ZH13785 & 49.00 & 55.00 & 6.00 & 158.67 & 98.33 & 9.73 \\
\hline 20 & ZH13728 & 51.50 & 55.00 & 3.50 & 147.17 & 93.83 & 9.71 \\
\hline 21 & ZH13695 & 50.00 & 53.50 & 3.50 & 172.17 & 97.50 & 9.64 \\
\hline 22 & ZH13737 & 52.50 & 54.50 & 2.00 & 143.83 & 77.50 & 9.61 \\
\hline 23 & ZH13817 & 53.00 & 56.00 & 3.00 & 173.83 & 94.67 & 9.56 \\
\hline 24 & ZH13988 & 55.00 & 57.50 & 2.50 & 154.83 & 78.83 & 9.53 \\
\hline 25 & ZH13608 & 50.50 & 55.50 & 5.00 & 163.33 & 91.17 & 9.50 \\
\hline 26 & ZH13889 & 53.00 & 55.00 & 2.00 & 159.33 & 88.33 & 9.50 \\
\hline 27 & ZH13706 & 53.00 & 56.50 & 3.50 & 169.67 & 98.00 & 9.45 \\
\hline 28 & ZH13727 & 54.50 & 57.50 & 3.00 & 153.83 & 84.17 & 9.44 \\
\hline 29 & ZH13774 & 49.00 & 52.50 & 3.50 & 154.33 & 94.50 & 9.44 \\
\hline 30 & ZH13628 & 52.50 & 55.00 & 2.50 & 158.33 & 79.17 & 9.42 \\
\hline 31 & ZH13701 & 50.00 & 52.00 & 2.00 & 169.67 & 88.83 & 9.42 \\
\hline 32 & ZH13739 & 54.00 & 58.50 & 4.50 & 173.33 & 90.17 & 9.42 \\
\hline 33 & ZH13748 & 52.00 & 54.50 & 2.50 & 162.50 & 95.83 & 9.42 \\
\hline 34 & ZH13966 & 53.50 & 56.00 & 2.50 & 168.00 & 94.33 & 9.41 \\
\hline 35 & ZH13642 & 49.50 & 51.00 & 1.50 & 168.17 & 99.33 & 9.38 \\
\hline 36 & ZH13799 & 53.50 & 56.00 & 2.50 & 162.33 & 90.83 & 9.33 \\
\hline 37 & ZH13787 & 52.00 & 55.50 & 3.50 & 164.33 & 93.33 & 9.32 \\
\hline 38 & ZH13650 & 50.00 & 53.00 & 3.00 & 187.83 & 98.67 & 9.27 \\
\hline 39 & ZH13587 & 52.50 & 55.50 & 3.00 & 172.00 & 100.67 & 9.26 \\
\hline 40 & ZH13644 & 51.50 & 54.00 & 2.50 & 180.04 & 107.00 & 9.26 \\
\hline 41 & ZH13713 & 52.50 & 56.50 & 4.00 & 156.50 & 98.83 & 9.23 \\
\hline 42 & ZH13696 & 49.50 & 52.50 & 3.00 & 168.17 & 99.67 & 9.20 \\
\hline 43 & ZH13548 & 55.50 & 59.00 & 3.50 & 161.13 & 93.83 & 9.15 \\
\hline 44 & ZH13915 & 54.50 & 57.50 & 3.00 & 169.17 & 95.33 & 9.15 \\
\hline 45 & ZH13732 & 50.00 & 52.50 & 2.50 & 162.67 & 88.33 & 9.14 \\
\hline 46 & ZH13550 & 50.00 & 53.00 & 3.00 & 169.33 & 94.33 & 9.06 \\
\hline 47 & ZH13731 & 51.00 & 53.00 & 2.00 & 167.33 & 100.17 & 9.05 \\
\hline \multicolumn{2}{|r|}{$31 Y 45$} & 54.50 & $\mathbf{5 5 . 5 0}$ & 1.00 & 174.83 & 93.50 & 11.35 \\
\hline \multicolumn{2}{|r|}{ Sample mean } & 51.90 & 55.09 & 3.18 & 165.66 & 93.41 & 9.78 \\
\hline \multicolumn{2}{|c|}{ Population mean } & $\mathbf{5 3 . 0 0}$ & 56.29 & 3.29 & 161.26 & 90.25 & 6.99 \\
\hline
\end{tabular}


The selected $\mathrm{F}_{2: 3}$ families in MPS 1 population under heat stress condition would provide maximum genetic gain for grain yield $(58.55 \%)$ followed by ear height $(5.49 \%)$, plant height $(4.25 \%)$, days to 50 per cent anthesis $(-2.05 \%)$, days to 50 per cent silking $(-2.24 \%)$ and ASI (-3.35\%). Whereas selected families of MPS 2 would provide maximum genetic gain for grain yield (39.91\%) followed by ear height $(3.50 \%)$, plant height $(2.72 \%)$, days to 50 per cent anthesis $(-2.02 \%)$, days to 50 per cent silking $(-2.07 \%)$ and ASI $(-3.45 \%)$.

Similar results were observed by Ranganatha (2015); he also reported maximum genetic gain for grain yield $(57 \%)$ and anthesis silking interval $(-51 \%)$ under heat stress condition. The traits viz., anthesis silking interval, plant height and number of kernels showed high correlation with grain yield under heat stress condition (Angadi, 2014). Thus, by selecting the families involved in producing these testcrosses, new and elite heat tolerant lines belonging to opposite heterotic group could be produced.

In this study, our results showed maximum genetic gain in grain yield in MPS 1 population as compared to MPS 2 population under heat stress condition. This could due to the difference in population size and level of inbreeding between the two heterotic groups under heat stress condition. These findings were in agreement with other studies that reported significant difference among the population for grain yield and plant height under drought stress (Beyene et al., 2016a). Ranganath (2015), who also reported differences between the populations for grain yield under heat stress condition. These selected $\mathrm{F}_{2: 3}$ families were submitted to formation of cycles for further study.

It is concluded that genotypic variability in testcrosses derived from MPS 1 differed significantly for grain yield alone while, MPS 2 showed significant variation among genotypes for all the characters studied, indicating the presence of variability for all the traits in the germplasm utilized for present study. The top 10 per cent of the $\mathrm{F}_{2: 3}$ families of MPS 1 and MPS 2 populations were selected based their testcross performance and subjected to genetic gain study. The genetic gain study revealed that maximum genetic gain was observed in MPS 1 population for all traits than MPS 2 population. These results suggest that, a new and advanced elite heat tolerance lines could be isolated from the early segregating progeny that produced very good testcrosses in different heterotic groups

\section{Acknowledgements}

Technical support and valuable germplasm provided for this study under 'Heat tolerant maize for Asia' project funded by United State Agency for International Development (USAID) is duly acknowledged.

\section{References}

Alam, A, M., Seetharam, K., Zaidi, P. H., Dinesh, A., Vinayan, M. T. and Nath, U. K., 2017, Dissecting heat stress tolerance in tropical maize. (Zea mays L.). Field Crops Res., 204: 110-119.

Angadi, S. 2014. Evaluation of maize (Zea mays L.) inbred lines and hybrids for heat tolerance. M. Sc. (Agri.) Thesis, Univ. Agric. Sci., Raichur, Karnataka (India).

Anonymous, 2018b. Ministry of Agriculture, Govt. of India. www.indiastat.com.

Anonymous, 2018a. World agricultural production. USDA, Washington, DC, pp. 1-31.

Apraku, B. B., Fakorede, M. A. B. and Oyekunle, M. 2014. Agronomic traits associated with genetic gains in maize yield during three breeding eras in West Africa. Maydica Electron. Publication, 
59: 49-57.

Battisti, D. S., Naylor, R. L. 2009. Historical warnings of future food insecurity with unprecedented seasonal heat. Science, 323: 240-244.

Beyene, Y., Semagn, K., Crossa, J., Mugo, S., Atlin, G. N., Tarekegne, A., Meisel, B., Sehabiague, P., Vivek, B. S., Oikeh, S., Alvarado, G., Machida, L., Olsen, M., Prasanna, B. M. and Banziger, M., 2016a, Improving maize grain yield under drought stress and non-stress environments in Sub-Saharan Africa using marker-assisted recurrent selection. Crop Sci., 56: 344-353.

Deryng, D., Conway, D., Ramankutty, N., Price, J. and Warren, R. 2014. Global crop yield response to extreme heat stress under multiple climate change futures. Environ. Res. Lett., 9: e034011.

Dinesh, A. 2015. Genetic architecture of reproductive traits in tropical maize under heat stress situation. M. Sc. (Agri.) Thesis, Univ. Agric. Sci., Raichur, Karnataka (India).

Dowswell, C. R., Paliwal, R. L. and Cantrell, R. P., 1996, Maize in the third world. West view press, pp. 1-37.
Lobell, D. B., Banziger, M., Magorokosho, C. and Vivek, B. 2011. Nonlinear heat effects on African maize as evidenced by historical yield trials. Nature Climate Change, 1: 42-45.

Mohammadi, R. 2012, Genetic gain in grain yield and drought tolerance of durum wheat breeding lines under rainfed conditions in iran. Acta Agronomica Hungarica, 60(4): 417-432.

Patterson, H.D. and Williams, E.R. 1976. A new class of resolvable incomplete block designs. Biometrika., 63: 83-90.

Ranganatha, C. N. 2015. Early generation testing in maize for heat stress tolerance. M. Sc. (Agri.) Thesis, Univ. Agric. Sci., Raichur, Karnataka (India).

Shaw, R. H., 1988, Climatic requirement. In: Sprague, G. F., Dubey, J. W. (eds.), Corn and Corn Improvement. American Soc. Agron., Madison, USA, pp. 609638.

Zaidi, P. H. Zaman-Allah, M., Trachsel, S., Seetharam, K., Cairns, J. E. and Vinayan, M. T. 2016. Phenotyping for abiotic stress tolerance in maize heat stress: a field manual, CIMMYT, Asia, Hyderabad, India. pp. 1-32.

\section{How to cite this article:}

Muttappa Hosamani, I. Shankergoud, P. H. Zaidi, Ayyanagouda Patil, M. T. Vinayan, P. H. Kuchanur, K. Seetharam and Somasekhar. 2020. Genetic Gain in Testcrosses Derived from Heat Tolerant Multi-parental Synthetic Populations of Maize. Int.J.Curr.Microbiol.App.Sci. 9(01): 2195-2205. doi: https://doi.org/10.20546/ijcmas.2020.901.249 